\title{
JÓZEF MARCINKIEWICZ (1910-1940) IN COMMEMORATION OF THE 60TH ANNIVERSARY OF HIS DEATH
}

\author{
KAZIMIERZ DĄBROWSKI \\ Institute of Mathematics and Physics, Technical University of Biatystok \\ Wiejska 45a, 15-351 Bialystok, Poland \\ EWA HENSZ-CHĄDZYŃSKA \\ Faculty of Mathematics, University of Eódź \\ Banacha 22, 90-238 Eódź, Poland \\ E-mail: ewahensz@math.uni.lodz.pl
}

Józef Marcinkiewicz was born on March 30th, 1910, in Cimoszka, a small village near Białystok, Poland. The date and place of his birth, as given by Antoni Zygmund in his well known article, are not only mistaken, but also differ in the two versions of the article: in Polish [7] and in English [1]. (At the end of this article we explain why they are wrong.) Marcinkiewicz's parents were Klemens and Aleksandra (née Chodakiewicz). In Cimoszka, the manor house of the Marcinkiewicz family and the surrounding buildings have been well preserved. Klemens Marcinkiewicz bought the house and about 30 hectares of land from the money he had earned in America. Józef Marcinkiewicz had a sister Stanisława, the eldest of the children, two older brothers, Mieczysław and Edward, and a younger brother Kazimierz.

At first, because of his poor health, Marcinkiewicz took private lessons at home. Next, he entered the fourth grade of the King Sigismund Augustus Gymnasium in Białystok. In Białystok, Marcinkiewicz lived in lodgings not far from his school-friend Zygmunt Krassowski. The father of the latter, Zenon Krassowski, was a mathematics teacher at the Gymnasium but Marcinkiewicz was taught by another teacher, Konstanty Kosiński. However, Zenon Krassowski had a great influence on the development of Marcinkiewicz's mathematical interests. As a pupil, Marcinkiewicz did not care very much for school mathematics; in his School Leaving Examination (Matura) he got a $\mathrm{C}+$. He was awarded his Matura certificate on June 22nd, 1930.

2000 Mathematics Subject Classification: Primary 01A70. 
In autumn 1930, Marcinkiewicz started studying mathematics at the Mathematics and Natural Science Department of the Stefan Batory University in Wilno (Vilnius). Right from the beginning he demonstrated a thorough knowledge of the subject and exceptional mathematical talent and attracted the attention of the following professors from Wilno: Juliusz Rudnicki, Stefan Kempisty and Antoni Zygmund. For the academic year 1931/32 Professor Zygmund, the youngest of the three, announced a course in the theory of trigonometric series preceded by an introduction to the theory of Lebesgue integration. This ambitious course was too difficult for an average second year student. However, to Zygmund's great pleasure, Marcinkiewicz asked for permission to take this course. That was the beginning of the scientific collaboration between these two mathematicians. At that time, in pre-war Wilno, close contact between the talented student and the young professor was natural and easy. Soon another mathematician, Konstanty Sokół-Sokołowski, later a Ph.D. and a Senior Assistant Professor in the Department of Mathematics, joined them.

In his memorial article [1, 7] Professor Zygmund presented Józef Marcinkiewicz as a tall, handsome boy, lively, sensitive, warm and ambitious, with great sense of duty and honour. Marcinkiewicz also had other fields of interest outside mathematics. Before entering the university he hesitated whether to choose Polish Literature or Mathematics. He was interested in music and painting, he wrote poetry. He liked company and liked to enjoy himself; he danced, swam and was a good skier. His health was not particularly good because he had weak lungs. He spent every holiday at home. His mother tried to treat his disease by feeding him well. He did horse riding himself in the winter to get some fresh air into his lungs.

However, mathematics was the most important thing for him. His fellow student, Stanisław Kolankowski, who studied physics at that time, says that Marcinkiewicz would break a conversation not about mathematics, explaining that he had just had an idea and that he had to think about it. Then he would say goodbye and go off, deep in thought. Nevertheless, Marcinkiewicz was an active student. He was a member of the Mathematics and Physics Circle and its president during the academic year 1932/33.

Marcinkiewicz graduated in 1933, after three years of study. His M.A. thesis consisted of his first original results in mathematics and contained, among other things, the proof of the new and interesting theorem that there exists a continuous periodic function whose trigonometric interpolating polynomials corresponding to equidistant nodal points diverge almost everywhere. These results, in a somewhat extended form, were presented two years later as his Ph.D. thesis [2].

After passing his M.A. examinations, Marcinkiewicz spent one year in military service (along with his fellow student, S. Kolankowski) and attended a military course in the First Infantry Division. To S. Kolankowski's mind, Marcinkiewicz treated his soldier's duties seriously but not without a sense of humour, as far as the disadvantages of military service were concerned.

After that period, Marcinkiewicz started working as assistant to Professor Zygmund in the Department of Mathematics of the Stefan Batory University in Wilno. Marcinkiewicz's scientific career was as rapid as his study. He got his Ph.D. degree in 1935 (obviously, Professor Zygmund was his supervisor). His early work attracted the attention of 
the experts in the subject both in Poland and abroad. The collaboration with Zygmund resulted in a number of publications. In the articles [1, 7] Antoni Zygmund has written: His scientific development was so rapid, and the originality of his ideas so great, that in some parts of my own field I may only consider myself as his pupil.

After getting his Ph.D. degree, Marcinkiewicz was granted a scholarship by the Fund for National Culture and spent the academic year 1935/36 in Lwów (Lvov). He collaborated mainly with Stefan Kaczmarz and Juliusz Schauder. At a later period Marcinkiewicz wrote a very interesting paper on the multipliers of Fourier series [4]. It originated in a problem posed by Schauder and is often quoted in the literature. It was probably through Kaczmarz that Marcinkiewicz became interested in problems of general orthogonal systems and wrote a series of papers on this subject.

In autumn 1936, Marcinkiewicz came back to Wilno to work as Senior Assistant Professor. Soon, in 1937, he presented his Habilitation thesis [3] and became an Associate Professor.

In early autumn 1938, Marcinkiewicz was again granted a scholarship from the Fund for National Culture and went to Paris, London and Stockholm. In November 1938 he met his close friend, Irena Sławińska, in Paris. Ms Sławińska recalls: He would go out of the cinema in the middle of the film saying that he had no time for entertainment. It was as if he knew that he was running out of time.

During his stay in Paris he was offered a professorship in one of the American universities. He declined as he had already accepted another offer from the University of Poznań (Poland).

In the six years of his academic work (with one year's break), Józef Marcinkiewicz wrote 55 articles adding up to 638 pages, including 19 articles in collaboration with other authors. Marcinkiewicz's works cover various areas of mathematics: real functions, trigonometric and general orthogonal series, interpolation theory and theory of trigonometric polynomials, functional analysis, probability theory and complex analysis.

The most important and deepest results of Marcinkiewicz are on interpolation theory. They were published in Studia Mathematica in 1936 and (see note [5]) without proofs. Marcinkiewicz sent a letter including the proof of the main theorem to Professor Zygmund. After the war, Antoni Zygmund recreated all the proofs and published them in paper [6]. Nowadays, the term Marcinkiewicz space is used in interpolation theory.

Let us continue the story of Marcinkiewicz's life. In the second half of August 1939, Marcinkiewicz stayed in England. The outbreak of war was imminent. In Poland the general mobilisation was announced. Despite his colleagues' advice to stay in England, he decided to go back to Poland. Leaving his home to fight for his country he handed a large volume of manuscripts to his mother. On September 2nd, the second day of the war, Professor Zygmund happened to meet Marcinkiewicz in the street in Wilno. Marcinkiewicz was wearing a uniform and was assigned to the 35 th division. This was the last time they saw each other.

Stanisław Kolankowski recalls: Józef Marcinkiewicz was a Second Lieutenant. He was a reserve officer assigned to the second battalion of the 205th infantry regiment. (...) The second battalion was the first troop of the Polish Army to get to Lwów. It was already there on September 12th and participated in the defensive actions until 21st September. 
We met for the first time on 20th September. (...) At night the German army started to leave their positions, and then the Soviet Army came. The Lwów defence committee decided to give the city up to the Soviet Army. The Soviets "temporarily interned" the officers commanding the defence of Lwów. (...). It was the 25th September. I found out that Józef Marcinkiewicz was in the same car with me. (...). The railway workers told us that we would be located in camps throughout the Soviet Union. Then I decided to flee from the transport along with two other officers from Lwów. I insisted that Marcinkiewicz go with us. He decided not to go. (...) The railway workers told us that we were going to Starobielsk (a small town near Kharkov in Ukraine). Just before the Polish-Soviet border at the Podwysokie station all three of us jumped off the train. I saw Józef Marcinkiewicz at ten p.m. for the last time.

About this episode Ms Irena Sławińska writes: His solidarity with his companions. He wanted to share their destiny. He wanted to face the most brutal reality - right to the end. He considered it to be his moral duty, and that was even more important to him than saving his own life or the thought of his parents.

In 1956 Marcinkiewicz's sister, Stanisława Lewicka wrote to Wiadomości Matematyczne (Mathematical News) that the family had received two postcards from the Starobielsk camp. The last one was dated March 1941 (an evident mistake in the year). Marcinkiewicz also sent some postcards and letters from Starobielsk to his close friends, including Professor Zygmund.

On a list of people interned by NKWD and "missing", the so-called Katyn list made by Adam Moszyński according to evidence from witnesses, the name "Marcinkiewicz" appears twice: as a prisoner of war from Starobielsk (Marcinkiewicz, infantry officer) and as a prisoner from the Kozielsk camp (Józef Marcinkiewicz, Lieutenant, Associate Professor).

The exact date and place of death of Józef Marcinkiewicz remain unknown because some official Soviet documents are inaccessible or destroyed. However, the different pieces of information we have obtained from different sources form a convergent system from which we may assume that Józef Marcinkiewicz was undoubtedly kept in the Starobielsk camp (registered under the id number 2160 in Soviet documents). Probably, the Soviets soon discovered how brilliant their captive was. They offered him some form of collaboration. Marcinkiewicz allegedly asked in a letter for his mathematical books and a copy of his Ph.D. certificate to be sent to him to the camp. Personally, we suppose that in the end Marcinkiewicz declined the Soviet offer. He was then murdered in Kharkov or was transported from Starobielsk to the Kozielsk camp, where active officers were kept and later executed in the Katyń forest near Smolensk (Russia). Whether we take it literally or symbolically, we may repeat the words of his sister, Stanisława Lewicka: He had the family patriotism in his blood. Grandson and great-grandson of insurgents, he shared their tragic fate and, as a member of his own generation, he died in Katyn.

After the Soviet invasion of Białystok in 1939, the Western Belorus Communist Party considered the Marcinkiewicz family to be particularly dangerous for the new government. Marcinkiewicz's parents were transported in June 1940 (or 1941) to the Soviet Union by the NKWD and six months later died of hunger in Buchar. Edward, transported to Siberia, joined the Polish army of General Anders and took part in the battle 
of Monte Cassino. The youngest brother, Kazimierz, one of the defenders of Lwów, returned to his family's house. Like Mieczysław and Stanisława, he was a member of the Polish underground during the Soviet and Nazi occupation and at the beginning of the Communist regime. In 1951 he was killed by security officers in an attempted escape from prison. It was he who dug up Józef's manuscripts from the soil in Cimoszka. They were unfortunately in a state of decomposition. Mieczysław was forced by communist authorities to sell the farm and move to a different place.

It is thus not at all strange that Stanisława Lewicka intentionally modified the data as to Józef's date and place of birth to prevent the authorities from associating Józef with his brothers engaged in the Home Army.

In his article about Marcinkiewicz Professor Zygmund has written: Despite the brevity of his period of mathematical activity, it has nonetheless left a definite mark on Mathematics, and but for his premature death he would probably have been one of the most outstanding contemporary mathematicians. Considering what he did during his short life and what he might have done in normal circumstances, his early death may be seen as a great blow to Polish Mathematics, and probably its heaviest individual loss during the Second World War.

He could have stayed in England, but in his opinion, this meant desertion. Instead, he chose to fight and thus became a martyr.

\section{References}

[1] J. Marcinkiewicz, Collected Papers, A. Zygmund (ed.), PWN, Warszawa, 1964.

[2] - Interpolating polynomials for absolutely continuous functions, Wiadomości Matematyczne 39 (1935), 85-125 (in Polish).

[3] - On the summability of orthogonal series, ibid. 44 (1938), 5-16 (in Polish).

[4] —, Sur les multiplicateurs des séries de Fourier, Studia Math. 8 (1939), 78-91.

[5] —, Sur l'interpolation d'opérations, C. R. Acad. Sci. Paris 208 (1939), 1272-1273.

[6] A. Zygmund, On a theorem of Marcinkiewicz concerning interpolation of operations, J. Math. Pures Appl. 35 (1956), 223-248.

[7] —, Józef Marcinkiewicz, Wiadomości Matematyczne 4 (1960), 11-41 (in Polish). 